\title{
A Combined Probabilistic Approach for Natural Hazards Assessment of Soil-Sewer Pipes (S-SP) Systems
}

\author{
Nabil KaziTani ${ }^{1,2^{*}}$ \\ ${ }^{1}$ Higher School of Applied Sciences of Tlemcen (ESSA-T), BP 165 RP Bel Horizon, 13000 Tlemcen, Algeria \\ ${ }^{2}$ RISAM Laboratory, Faculty of Technology, University of TlemcenAbou-BekrBelkaid, Algeria
}

\begin{abstract}
The structural failure prediction of underground sewer pipes systems seems very complicated due to the natural hazards of soils in which these elements are buried. The apparition of first cracks and notches in sewer pipes parts is governed by the interaction model of soil-sewer pipes system (S-SP)parameters mainly, the constitutive material laws of soil and sewer pipe materials. The detection of critical sections where the structural damages are highly probable is the focus point of this present study. Based on probabilistic analysis of stochastic modelling results (Monte Carlo Method) of random soil properties, the mechanical behaviour of a part of sewer pipe is analysed in terms of settlements and flexural stress distribution fluctuations. A parametric study is performed to quantify the effect of correlation length (Lc) and soils types on the structural reliability of underground sewer pipes. This current structural analysis offers to engineers and researchers a useful numerical tool in order to allow them the well understanding of the structural behaviour of buried sewer pipes by considering the spatial variability of soil geo-mechanical characteristics which reflects the soil natural process of formation, its aggregation and heterogeneity. The obtained numerical results show that the probabilistic analysis of the spatial variability of soil properties into structure numerical modelling of sewer pipes presents an accurate approach for the prediction of structural responses of waste water transportation infrastructures particularly, if the sewer pipe lengths are relatively significant and buried into several classes of soils along sewer pipe networks.
\end{abstract}

\section{Introduction}

Sewer pipe networks are the ones of the most important elements urban and industrial infrastructures. Any structural failures or damages in these systems can cost the environment important disasters. The optimal modelling of the structural behaviour of buried sewer pipes can helps to obtain a suitable design based on soil characteristics data base along sewer pipes. Soil heterogeneity which it is characterized by its spatial variability is resulting from the history of soils and there aggregation processes. These inherent or natural hazards are highly significant for the case of the superficial construction works inducing differential settlements, whose consequences on structural behaviour can be unsafe: local failures, cracking and notching, leakage in sewers,...etc.The spatial variability of soil geomechanical characteristics and uncertainty related to imperfect knowledge in properties of soil and/or of the buried structure are the major source of uncertainty in the choice of the design soil parameters. In this area, a consequent number of research works have been carried out based on numerical models related to soil-structure interaction mechanisms such as; Fenton and Griffiths [1], SM. Elachachi [2],D.Nedjar et al. [3], A. Srivastava and Sivakumar [4], D. Breysse [5], E. Zlatanović et al. [6], M. Zoutat et al. [7],W.Tara and Minna [8],B.Basmaji et al. [9], Imanzadeh et al. [10], N.KaziTani et al. [11-12]. Prediction of structural damages and failure analysis of buried spread foundations, based on fracture mechanics concepts and soil-structure models, have been investigated recently by N.KaziTani et al. [13-14]. In this present paper, we target to present a numerical approach based on the combination between deterministic methods of structural analysis and probabilistic modeling of random soil characteristics. The current numerical study can be significantly useful to predict critical sections in sewer pipe networks mainly at the interfaces where soil geomechanical properties affects significantly the rigidity of (S-SP) system.

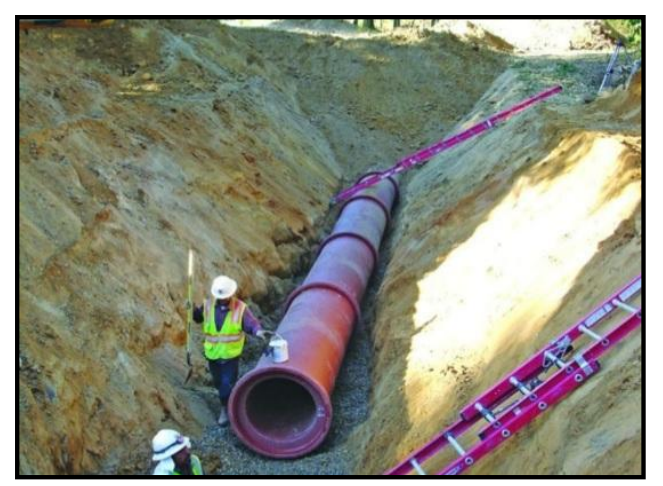

Fig. 1.Excavation and installation of sewer pipe line

2Governing equations of (S-SP)system

*Corresponding author: kazitani_nabil@yahoo.fr 
The modelling of structural behaviour of soil-sewerpipe (S-SP) systems (Fig.1) can be carried out by the following relationshipsin terms of verticaldeflections $y(x)$, soil subgrade modulus $K_{s}(x)$ and flexural rigidity $E_{p} I_{p}$ of the buried sewer pipe(Fig.2).

$$
\frac{d^{2}}{d x^{2}}\left(E_{p} I_{p} \frac{d^{2} y(x)}{d x^{2}}\right)=-K_{s}(x) y(x)
$$

From which

$$
y+\frac{l_{0}^{4}}{4} \frac{d^{4} y(x)}{d x^{4}}=0
$$

Where $l_{0}$ is given by (Eq.3) as a function of pipediameterD as follows,

$$
l_{0}=\sqrt[4]{\frac{4 E_{p} I_{p}}{K_{s} y(x) D}}
$$

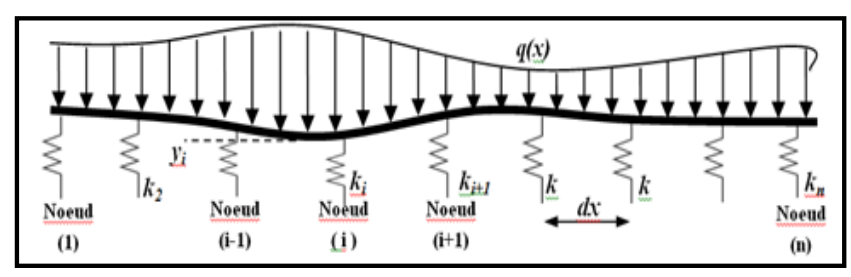

Fig. 2.Discrete model of a part of (S-SP) system

The general solution of the above differential equation (Eq.2) is of the form:

$$
\begin{aligned}
y(x)= & e^{\frac{-x}{l_{0}}}\left(a_{1} \cos \frac{x}{l_{0}}+a_{2} \sin \frac{x}{l_{0}}\right) \\
& +e^{\frac{x}{l_{0}}}\left(a_{3} \cos \frac{x}{l_{0}}+a_{4} \sin \frac{x}{l_{0}}\right)
\end{aligned}
$$

The values of $\mathrm{a}_{1}, \mathrm{a}_{2}, \mathrm{a}_{3}$ and $\mathrm{a}_{4}$ can be obtainedy considering the boundary conditions of the (S-SP) system.

\section{Modelling ofsoil natural hazards}

Soil natural spatial heterogeneity result from its natural process of formation and its aggregation, has been considered. This random aspect is modeled through probabilistic methods based on Monte Carlo approach.In order to quantify the effect of soil spatial variability, the adopted approach consists to combine the finite differences method for resolving numerically the governing differential equation (Eq.1) above with the possibilities of stochastic modeling of soil subgrade reaction modulus.

These stochastic methods are essentially of two families, mainly the disturbance methods and Monte Carlo method based on three steps:

- Discretization of random field
- Analysis bydeterministic method of structural analysis

- Statistical analysis of structure responses after having carried out a consequent number of simulations for each achievement.

The variation of the soil geo-mechanical characteristics can be properly described by the VanMarck[15] theory of local average. The random field of the soil subgrade modulus $\mathrm{K}_{\mathrm{s}}(\mathrm{x})$ is described by its average, its variance and the correlation lengthLcwhich is defined as the distance beyond which the spatial correlation, between properties, is lost. In a zone (i) of a length $D_{i}$, the variance of $K_{s}$ is expressed as follows:

$\operatorname{Var}\left[k_{\text {sol }}\left(D_{i}\right)\right]=\sigma_{k}^{2} \gamma\left(D_{i}\right)(5)$

And their local averages are respectively:

$E_{S}\left[k_{\text {sol }}\left(D_{i}\right)\right]=m_{\kappa}(6)$

The average $m_{k}$ is considered as constant for the entire field. The variance function $y$ of the entire field of $\mathrm{K}_{\mathrm{s}}(\mathrm{x})$ is expressed as follows:

$\gamma\left(D_{i}\right)=\frac{2}{D_{i}} \int_{0}^{D_{i}}\left(1-\frac{x}{D_{i}}\right) \psi(x) d x(7)$

$\gamma\left(D_{i}\right)$ represents the measurement of the variance reduction due to the average random process according to the length of the considered zone and is related to the correlation function $\psi(\tau)$, which varies between 0 and Lc and given by:

$\psi(\tau)=1-\frac{|\tau|}{L_{c}}(8)$

From equations (7) and (8), the variance function can be obtained

$\gamma\left(D_{i}\right)=\left\{\begin{array}{c}1-\frac{D_{i}}{3 L_{c}} \text { if } D_{i} \leq L_{c} \\ \frac{L_{c}}{D_{i}}\left(1-\frac{L_{c}}{3 D_{i}}\right) \quad \text { if } D_{i} \geq L_{c}\end{array}\right.$

Therefore, it is easier to construct a random field for the whole system through co-variance matrices $C_{i j}$ of soil reaction coefficients corresponding to the correlation between two zones of length $\mathrm{D}_{\mathrm{i}}$ and $\mathrm{D}_{\mathrm{j}}$.

$C_{i j}=\frac{\sigma_{k}^{2}}{2}\left[(t-1)^{2} \gamma[(t-1) D]-2 t^{2} \gamma(t . D)+\right.$ $(t+1)^{2} \gamma[(t+1) D](10)$

Where $t=i-j$ and $i, j$ represent the zone numbers.

\section{Elasto - Plastic soil behaviour}

Soil material behavior is incorporated in the proposed numerical model and governed by the popular nonassociated Mohr-Coulomb criterion largely used in geotechnical engineering practice (Figure. 2) where Pmax and ye are obtained through relations below in terms of major and minor principal stresses $\sigma_{1}$ and $\sigma_{3}$. 
cand $\varphi$ are respectively the cohesion of the soil and its friction angle.

$$
\begin{gathered}
\mathrm{P}_{\max }=2 \mathrm{c} \cdot \cos \varphi-\left(\sigma_{1}+\sigma_{3}\right) \sin \varphi \\
\mathrm{y}_{\mathrm{e}}=\frac{\mathrm{P}_{\max }}{\mathrm{K}_{\mathrm{s}}}
\end{gathered}
$$

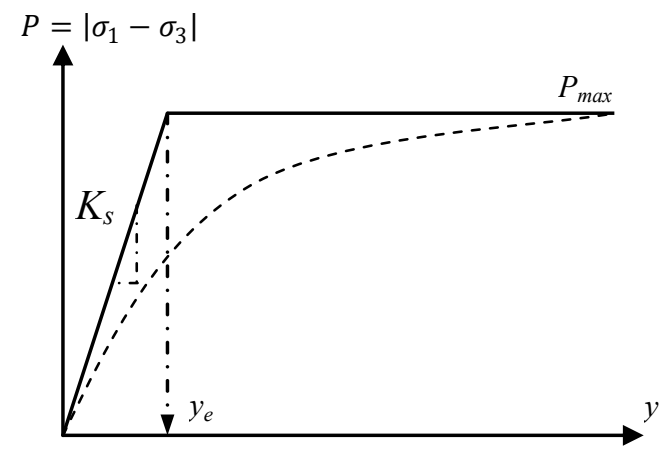

Fig.3.Elastic Perfectly Plastic soil model.

\section{Results and discussions}

The obtained numerical results presented in this section concern a (S-SP) system of $60.0 \mathrm{~m}$ length made with reinforced concrete (RC)sewer pipe of $1.0 \mathrm{~m}$ diameter. The system is simply supported at the ends, laying onvariable elastic supports subjected to a uniformly distributed load resulting from the self-weight of sewer pipeand backfill soil. The numerical analysis was carried out by considering bothof the spatial variability of soil characteristics and its Elasto-Plastic behavior model governed by non-associative Mohr-Coulomb criterion (EPP).For the case of soft clay soil [16] [17] [18], Table 1 bellow summarizes the main mechanical properties of (S-SP) system materials used in the simulation.

Table 1. Materials characteristics of (S-SP) system

\begin{tabular}{|l|c|c|}
\hline & $\begin{array}{c}\text { Concrete } \\
\text { sewer pipe }\end{array}$ & $\begin{array}{c}\text { Soil } \\
\text { characteristics }\end{array}$ \\
\hline $\mathrm{E}[\mathrm{MPa}]$ & 30000 & 6.0 \\
\hline Poisson ratio, $v$ & 0.20 & 0.40 \\
\hline Cohesion $[\mathrm{MPa}]$ & - & 0.0125 \\
\hline $\mathrm{K}_{\text {soii }}\left[\mathrm{MN} / \mathrm{m}^{3}\right]$ & - & 3.067 \\
\hline
\end{tabular}

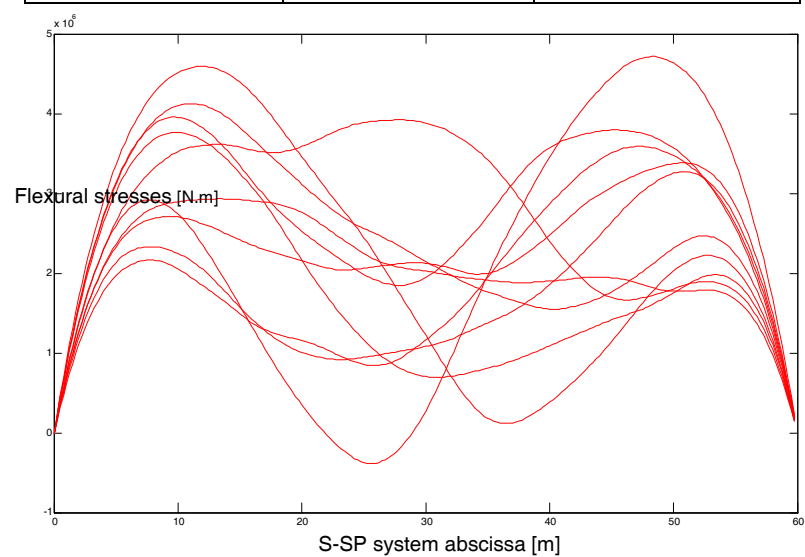

Fig. 4. Flexural stress distribution along sewer pipe for some hazards of soil geo-mechanical characteristics

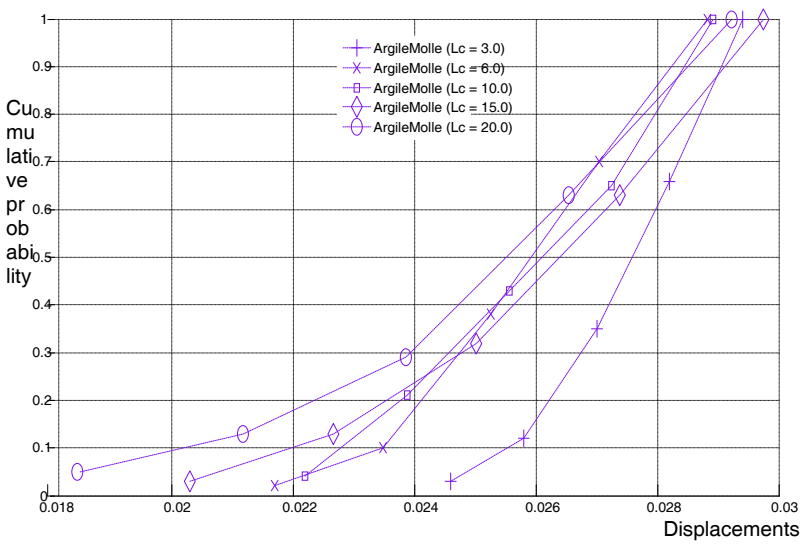

Fig.5. Cumulative distribution functions of sewer pipe ultimate settlements for several values of correlation length $(\mathrm{Lc}=3.0 \mathrm{~m}$, $6.0 \mathrm{~m}, 10.0 \mathrm{~m}, 15.0 \mathrm{~m}, 20.0 \mathrm{~m})$

The plotted results above show the structural responses of the sewer pipe by taking into account the variability of the soil as a function of the bending and deflection stresses. For all the simulations carried out, the obtained curves represented above form an envelope of the ultimate values of the sewer pipe structural responses (Fig.4) which helps to obtain an optimal dimensioning of sewer pipe sections. The cumulative distribution functions (Fig.5) are presented to quantify the probabilities of the ultimate deflections the 200 simulations and direct the design of the sewer pipe towards the most optimal dimensioning based on the most representative internal forces that are related to the distribution of rigidities at the sewer pipe-soil interfaces. The values of the correlation length Lc and the number of simulations have a significant influence on the calculation of the sewer pipe structural responses and their choices must be done based on a particular analysis depending on the nature of the buried structure and its topology.

\section{Conclusions}

Soil variability along the soil- sewer pipe (S-SP) system networks was incorporated thought this present numerical investigationin order to perform the structural analysis based on the theory ofVanMarcke'sof local average [15] for the random field. The main important parameters governing the mechanical behaviour of the buried sewer pipes, namely, the geo-mechanical properties of the soil and their variability as well as the fluctuation lengthsLc allow designers to assess the structural risks that can affect the network sewer pipes systems by limitingsome characteristics values related to flexural displacements and stresses.

\section{References}

1. Fenton, GA., Griffiths DV.J GeotechGeoenviron128, 5(2002) 
2. Elachachi, S. M., Breysse, D., \&Houy, L. ComputGeotech31(2004)

3. Nedjar, D., Hamane, M., Bensafi, M., Elachachi, S. M. and Breysse, D. Soil DynEarthqEng27(2007)

4. Srivastava, A., SivakumarBabu, GL.Eng. Geol.108(2009)

5. Breysse, D., Revue Française de Génie Civil6, 3 (2011)

6. Zlatanović E., Lukić D Č.,Prolović V.,Bonić Z., Davidović N.Eur J Environ Civ En19, 8 (2015)

7. Zoutat M., Elachachi S.M., Mekki M., Hamane M.Eur J Environ Civ En22, 2 (2018)

8. Wood T., Karstunen M. Eur J Environ Civ En (2017)

9. Basmaji B., Deck O., Al Heib M. Eur J Environ Civ En23, 3 (2019)

10. S. Imanzadeh, D. Breysse, J. Baroth, D. Dias, N. Piegay\& S.M. Elachachi.Georisk: Assessment and Management of Risk for Engineered Systems and Geohazards (2019)

11. KaziTani, N., Nedjar, D., Hamane, M. Eur J Environ Civ En 17, 9 (2013)

12. Nabil KaziTani, D. Nedjar, T.Tamine, M. Hamane. Journal of Materials and Engineering Structures, 6, 2, (2019)

13. KaziTani, N., Nedjar, D., Tamine, T., Hamane, M.Arab J Sci Eng42, 3 (2017)

14. KaziTani, N., Tamine, T. \&Pluvinage, G. Arab J Sci Eng (2019). https://doi.org/10.1007/s13369-019-03926-3

15. E.VanMarcke, Random fields: analysis ans synthesis, Cambridge, MA, London, England: MIT (Press, 1983).

16. H.F. Winterkorn, K.Y. Fang, Fondation Engineering Handbook, Van Nostrand Reinhold Company (Press, 1975).

17. T.W Lambe, R.V. Whitman, Soil Mechanics (Press, 1969) John Wiley (M.I.T.)

18. G. Filliat, La pratique des sols et fondations (Press, 1981), Edition du Moniteur. 